\title{
La ineficacia de los estados en la corrección de los fallos del mercado mundial*
}

\author{
Oscar Mascarilla i Miró \\ Universidad de Barcelona. Facultad de Economía y Empresa. \\ Departamento de teoría económica. \\ Av. Diagonal n $n^{\circ} 690$ - 08034 Barcelona
}

\section{INTRODUCCIÓN}

La característica más determinante de la globalización de principios del siglo $\mathrm{xx}$ y principios del siglo XxI ha sido las fuerza incontrolable de un mercado financiero no regulado y su poder para interrelacionar las distintas economías mundiales. El fenómeno, además de otros aspectos controvertidos, ha originado efectos que merman y reducen el ámbito de aplicación, y por lo tanto la eficacia de políticas económicas convencionales que llevan a cabo los estados, básicamente de tipo monetario, cambiario y comercial.

El presente trabajo se circunscribe, y toma como punto de partida, ideas planteadas parcialmente en el los trabajos de Summers (1999), Rodrik (2000) y Rodrick, D. \& Ypersele (2001) incorporando los problemas de política de estabilización macroeconómica que llevan a cabo los países.

Con este objetivo el punto 2 plantea como la no coincidencia del ámbito territorial decisorio de lo político con el ámbito territorial decisorio de lo económico conlleva aspectos colaterales de la globalización que derivan de la dificultad política de corregir los fallos del mercado mundial. Siguiendo el hilo conductor el punto 3 analiza la globa-

* El trabajo ha sido realizado al amparo del proyecto de investigación ECO2008-04997/ ECON del plan nacional de I+D+i, cuya financiación agradece el autor. 
lización, como un escenario que reduce la eficacia de determinadas políticas económicas convencionales propiciando reiteradas situaciones de inestabilidad macroeconómica y enfatizando la dificultad de mantener simultáneamente tres aspectos económicos inicialmente deseables para los países como son: la estabilidad del tipo de cambio, la autonomía en política monetaria y la disponibilidad de recursos financieros externos. El punto 4 muestra la situación de inestabilidad macroeconómica fruto de la dimensión financiera de la globalización y su repercusión en los mercados de commodities ${ }^{1}$. Finalmente se establecen las diferentes conclusiones del trabajo.

\section{LA DIFICULTAD DE CORREGIR LOS FALLOS DEL MERCADO MUNDIAL}

La creciente asimetría geográfica entre la esfera económica-financiera-empresarial y la esfera socio-política plantea una situación de dilemas triples en lo político-social. La idea es que tres aspectos inicialmente deseables para cualquier país como son acceder a la senda de crecimiento que posibilita la globalización económica y financiera, disfrutar de las prerrogativas de la soberanía nacional y mantener la viabilidad de un estado de bienestar nacional y mundial con estabilidad económica, es difícil de conseguir simultáneamente.

La teoría económica califica la globalización económica y financiera como deseable por motivos de «eficiencia» (dimensión económica). La defensa de la soberanía nacional se basaría en el sentido de estados-nación garantes de unos contratos sociales o «cobertura» a los ciudadanos frente a riesgos e incertidumbres, además del sentido de identidad nacional y de representación política argumentando que la gente valora que las decisiones sobre su persona se tomen cerca de uno (dimensión política). Por último, es deseable la estabilidad económica, un estado del bienestar mundial y la protección

${ }^{1}$ Aunque el argot «Commodities» se utiliza para denominar al mercado de productos agrícolas, energía y de materias primas para la industria, también se aplica desde un punto de vista financiero para denominar todo aquello que sea subyacente en un contrato de futuros de una bolsa de commodities o en general de mercados organizados donde cotizan, metales utilizados en procesos industriales (cobre, hierro, níquel ó zinc), metales preciosos, principalmente el oro y la plata, energía (petróleo, carbón, gas), alimentos e insumos (azúcar, algodón, madera, café, naranjas), bienes agrícolas (maíz, trigo, garbanzos, soya, etc) o ganado (cerdo, vacuno), etc. Entre las bolsas especializadas destaca la de Chicago o la Bolsa de Metales de Londres. 
social (dimensión social) con una corrección de los fallos del mercado mundial tal y como se refleja en los vértices de la figura 1.

Figura 1. Los dilemas triples de la globalización en los político-social

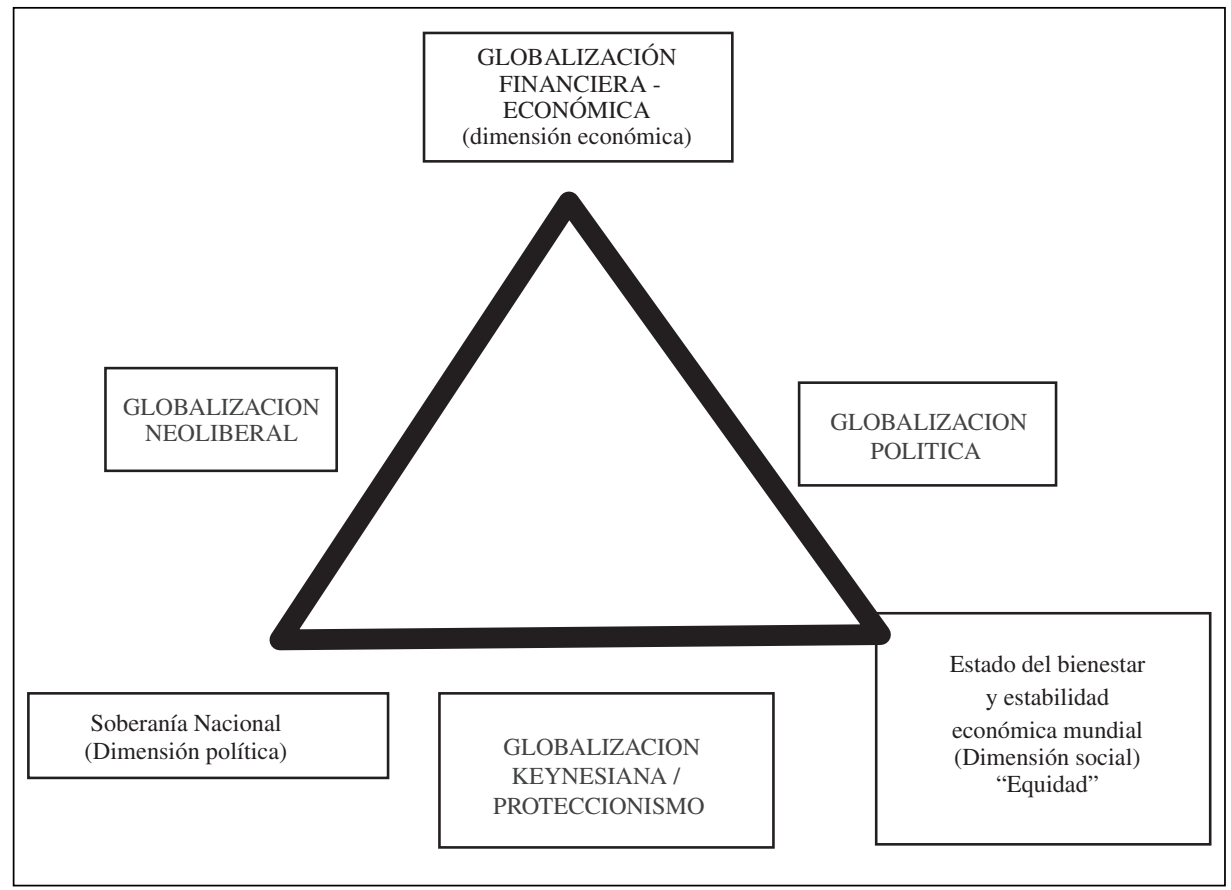

En este escenario se vislumbran 3 diferentes opciones de política económica posibles. Seguir con la globalización neoliberal con un mercado mundial y financiero desregulado en el que las empresas pueden elegir cualquier ubicación y pueden invertir en cualquier parte del mundo, con una esfera económica-financiera-empresarial globalizada, quedando por el contrario y subsistiendo la esfera socio-política enmarcada todavía en el ámbito estatal. En este contexto, ¿qué ocurre?: que las empresas y el capital aumentan su poder frente los estados y los sindicatos. De modo que, mientras haya asimetría entre las dos esferas, ocurrirá por ejemplo que si en un país A los costes salariales son elevados o en ese país las medidas medioambientales son muy estrictas o en ese país se pagan más impuestos, las empresas pueden decidir trasladar su producción o los capitales. Por consiguiente, los aspectos colaterales al fenómeno de la globalización actual son una situación en que las transnacionales pueden transferir capitales 
y empleo desde los países desarrollados a otros países del mundo con costes salariales y no salariales más bajos, con los problemas de viabilidad del estado de bienestar que ello conlleva (reducción de impuestos) y con fallos del mercado mundial no corregidos (crisis financieras, medioambientales, de seguridad o pobreza extrema en determinados países). Un escenario de competencia, en el que desaparece el concepto de seguridad y los fallos del mercado mundial se van sucediendo.

Precisamente, y con más relevancia con la acentuación de la crisis de 2009, diferentes grupos sociales ven en la globalización neoliberal una merma del potencial de los Estados para seguir cumpliendo sus compromisos frente la población, cuya relevancia se ve acentuada por los cambios e incertidumbres que la propia crisis está suponiendo sobre las economías y los mercados de trabajo. Es este miedo a perder el contrato social del Estado de Bienestar el que permite explicar los recelos, incertidumbres y vacilaciones respecto al proceso de mundialización. En concreto con un afán de reformular el capitalismo se han realizado planteamientos de política económica que van desde una mayor regulación de los mercados hasta otras de corte más radical que apuestan por un mayor proteccionismo².

De todo el planteamiento realizado podemos llegar a la conclusión que, hoy, los Estados-nacionales se encuentran en una profunda contradicción: la de defender los intereses de sus empresas transnacionales (o atraerlas si no las tienen) y la de defender los intereses nacionales cuyo ámbito de actuaciones limita al mercado nacional.

Por consiguiente, los aspectos colaterales al fenómeno de la globalización son una situación de dilema del prisionero donde si cada país actúa en función de sus intereses se llega al peor de los resultados posibles en términos sociales, pérdida del estado de bienestar o fallos del mercado mundial no corregidos. Es la opción actual que relaja los Estados de Bienestar que lleva a un escenario de competencia, en el que desaparece el concepto de estabilidad y seguridad y los fallos del mercado mundial se van sucediendo.

Parece que las dos anteriores opciones de política económica (opción liberal y keynesiana o proteccionista ) sean los únicos debates posibles, esto es, el debate histórico (no resuelto aún hoy) entre: ¿Son mejores las políticas de eficiencia o las de equidad?. Pero según el «trilema» habría una tercera vía, que consistiría en moverse hacia un «fe-

2 En este sentido destacar algunos los discursos con matiz proteccionista que a principios de 2009 han aflorado en Estado Unidos, en el Reino Unido, en Francia o España tanto desde la perspectiva de proteger a los trabajadores nacionales frente a los extranjeros, como en el de favorecer el consumo de bienes nacionales, o favorecer a la inversión nacional. 
deralismo global». Parece razonable que una economía global necesita de una política global (al igual que cuando la economía era nacional la política requerida para corregir los fallos del mercado debía ser nacional).

Asimismo, en gran parte la dinámica de la globalización origina una creciente polarización, una creciente desigualdad dentro de y entre los países, ello requiere algunos mecanismos de compensación política y social «razonables». Es decir, requiere la articulación de políticas a nivel intergubernamental en materias como la financiera, fiscal, laboral y medioambiental.

\section{Globalización FinANCIERA E INESTABILIDAD MACROECONÓMICA}

Donde la globalización ha ejercido realmente una gran influencia es en el ámbito del sistema financiero internacional, debido principalmente a que la libre movilidad de capitales se manifiesta a todos los niveles (inversión extranjera directa, internacionalización de la banca, conexión de bolsas y plataformas de contratación, universalización de la innovación financiera). El terreno abonado para ese gran condicionamiento es el resultado, al menos, de tres circunstancias:

Primera, la transformación de los mercados, que a partir de la implantación de los «eurodólares» en los años sesenta empuja la aparición de mercados no regulados, a lo que se suman las revolucionarias transformaciones tecnológicas en el seno de los mercados organizados, en un contexto que secuencialmente se agranda por la necesidad de disponer de espacios adecuados para el reciclaje de excedentes de recursos financieros de países productores de petróleo, por la agresiva irrupción de las plataformas contractuales del sudeste asiático, por la popularización de la inversión bursátil y por los importantes avances en la información y en las telecomunicaciones.

La segunda circunstancia se deriva de la aparición masiva y sofisticada de nuevos productos e instrumentos financieros. Ello es consecuencia, al margen de la propia evolución sectorial, de la adopción generalizada a partir de 1973 de tipos de cambio flexible, que origina fuertes incrementos de riesgo que tienen que ser contrarrestados con novedosos productos de cobertura que se van generalizando en otros ámbitos en forma de mercados de derivados — opciones y futuros - También, en esta dirección, el hecho de que, al margen de su repercusión sobre la estructura de los respectivos mercados, se incrementa el diseño y posterior adopción de instrumentos específicos para disponer de garantías aceptables para la financiación de las muchas emisiones de deuda consecuencia de los abultados déficits públicos. 
Y, tercera circunstancia, el cambio en la naturaleza de los agentes actuantes. Efectivamente, la liquidez internacional en manos de grandes de operadores privados, con lo que ello supone de merma de la tradicional hegemonía de instituciones públicas. De esta forma, los efectos de la globalización refuerzan la autonomía funcional de los mercados implicados, en detrimento de reglamentaciones, procedimientos e, incluso, de los reguladores que desde finales de los años 1940 regían las contrataciones y orientaban sus actuaciones, en contraste con lo que sucede en la actualidad, a objetivos y prioridades de tipo público (políticas sociales, de cooperación, de bienestar, etc.).

Los movimientos internacionales de capital, en especial a corto plazo, han ejercido una influencia decisiva sobre los tipos de cambio y la volatilidad del ciclo financiero en diversos países. Habida cuenta de las distorsiones que introducen ha resultado afectada la eficacia de políticas nacionales de estabilización macroeconómica, en el sentido de generar conflicto para conseguir simultáneamente la estabilidad del tipo de cambio, el acceso al capital financiero internacional y la autonomía de la política monetaria. Son tres dilemas triples de política macroeconómica que surgen de una situación en que ante tres aspectos, inicialmente deseables, se constata la imposibilidad de obtener los tres. Siendo preciso, por consiguiente, renunciar a un vértice. En los vértices de la figura 2 se detallan los tres aspectos deseables para cualquier país.

En este sentido la principal razón a favor de un sistema financiero internacional es el facilitar una asignación más eficiente de los recursos a nivel mundial, al permitir mejorar la eficiencia de la canalización del ahorro mundial a la inversión mundial, superando los «desequilibrios nacionales». Por otro lado, la estabilidad del tipo de cambio también es deseable ya que favorece el comercio y el flujo de inversiones de un país gracias a la eliminación de la incertidumbre (asociada a la no variación de los tipos de cambio de las monedas) y también la autonomía de un país en política monetaria es deseable ya que permite corregir desajustes macroeconómicos particulares del país.

El «trilema» consiste en la imposibilidad de mantener simultáneamente estos tres vértices deseables de la figura 2 ilustrando cada costado las 3 diferentes alternativas de política económica posibles en un mundo global que han conllevado situaciones históricas de inestabilidad macroeconómica.

Para acceder con fluidez a los mercados financieros y garantizar, a la vez, estabilidad del tipo de cambio (permitiendo controlar la inflación y otorgar a los inversores disciplina fiscal y un seguro de cambio gratuito) es preciso adoptar una política de $\mathrm{cu}$ rrency board, renunciando a la instrumentación de una política monetaria propia a nivel nacional. En efecto, si se adoptan las prescripciones del «currency board»y, por lo tanto, la evolución de la oferta monetaria depende exclusivamente de la disponibilidad de reservas de la moneda de referencia, la aplicación de ajustes de tipo de interés como 
medida anticíclica deviene impracticable porque su misión no es otra que contribuir a mantener la paridad cambiaria.

Figura 2. Los dilemas triples de la globalización en política económica



Este tipo de sistema ha sido aplicado por diferentes países por diversas razones. Puede aplicarse por motivos históricos y financieros, como es el caso de las excolonias británicas de Hong Kong, segunda plaza financiera asiática o de las islas Bermudas, paraíso fiscal muy vinculado a los EE.UU. Lo han aplicado países con graves problemas de inflación con el objetivo de que su tasa de inflación convergiera a la del país de la moneda ancla de referencia, como es el caso de Argentina ${ }^{3}$ y Bulgaria, o también lo

3 Argentina, 1991-2001, fijó la evolución de la oferta monetaria del país a la evolución de las reservas en dólares, con el fin de mantener un tipo de cambio fijo entre el peso argentino y el dólar en la proporción 1:1. Argentina perdió autonomía en política monetaria nacional y subordinó la economía argentina a la política monetaria de Estados Unidos. Y esto fue traumático cuando los intereses de Estados Unidos no coincidieron con los que necesita el país. La combinación tipo de 
han adoptado pequeños países recién independizados de la antigua URSS con el objetivo de que sus economías convergieran lo más rápidamente posible hacia niveles de tasas de inflación occidentales, acelerando así su proceso de transición a la economía de mercado y su futura integración en la Unión Europea, como es el caso de Estonia y Lituania. También fue el caso de muchos países de América Latina y del Sistema Monetario Europeo anterior al euro (interpretado en algún momento como un enfoque de «currency board» de España e Italia, respecto del marco alemán a escala mucho menor $)^{4}$. Bermudas, Hong Kong, Argentina, y Lituania han utilizado como moneda ancla al dólar USA, mientras que Estonia y Bulgaria tenían al marco alemán en su origen siendo sustituido a partir del 1 de enero de 1999 por el euro.

Por otro lado los países que deseen manejar la tasa de interés sin afectar el movimiento de capitales, no pueden mantener la estabilidad del tipo de cambio. Especialmente para determinados países, la combinación de intereses regulados con libre movimiento de capitales se acaba pagando con disminución del flujo de capitales (pues los intereses son reducidos) y, posiblemente, con inflación. Esto es así, al menos, en países (como Argentina), con «déficit mellizos» (fiscal y de cuenta corriente), instituciones monetarias desprestigiadas, exagerada deuda externa y elevado endeudamiento interno en moneda extranjera. Además, disponer de política monetaria propia a nivel nacional y acceder al mismo tiempo al mercado internacional de capitales, no garantiza la estabilidad de tipo de cambio, pues, como consecuencia de las obvias fluctuaciones cambiarias, deberán adoptarse medidas correctoras que llevan al establecimiento de tipos de cambio flexibles para evitar pérdidas de competitividad. La volátil evolución del dólar con el euro en los últimos años muestra la idea.

De hecho es posible proveer la estabilidad del tipo de cambio y disponer de política monetaria propia restringiendo el acceso a los mercados financieros internacionales, debiéndose entonces arbitrar mecanismos de control de capitales. Esto es, si el gobierno quiere manejar la tasa de interés o mantener autonomía en política monetaria nacional y quiere mantener estabilidad del tipo de cambio, es preciso un control de capitales tal y como sucedió en la primera etapa de Bretton-Woods, o en cierto modo en la actual China, a costa de poder perder acceso al capital financiero internacional y

cambio fijo con libre movimiento de capitales se pagó con pérdida de competitividad e intereses altos: premio para los especuladores y castigo para los productores.

${ }^{4}$ Ni España, a partir de septiembre de 1992 (a pequeña escala), ni México (a un nivel alto) a partir de diciembre de 1994, pudieron mantener el tipo de cambio al nivel estable al cual se habían comprometido. 
con una posible pérdida de competitividad si los controles interrumpen o disminuyen drásticamente el flujo de capitales (los bajos intereses internos son insuficientes para compensar la ausencia de capital).

Como se señala en Rodrik, D. \& Ypersele (2001), el problema subyacente en este contexto es la no existencia de unas reglas estrictas que regulen el funcionamiento del sistema monetario internacional, de modo que el movimiento de capitales a corto plazo, imprime una gran dinámica en la determinación de los tipos de cambio (las monedas se adquieren como un activo financiero más $)^{5}$ dando lugar a repetidas crisis financieras.

Las tormentas monetarias en Europa que afectaron de forma singular al sistema monetario europeo en 1992 y 1993; la crisis iniciada en México en 1994 y que se extendió en 1995 a parte de América Latina, dando lugar al denominado efecto tequila, la amplia crisis iniciada en 1997 en los países del Sudeste asiático y que se extendió en 1998 y 1999 a otros ámbitos geográficos, incluidos Japón, Rusia y Brasil y la más reciente crisis financiera Argentina 2001-2002 constituyen ejemplos y testimonian el alcance y las profundas implicaciones que las nuevas reglas del juego pueden tener, con el subsiguiente debate generado sobre la actuación, ante esos problemas, del Fondo Monetario Internacional y otros organismos internacionales denotando las dificultades de los Bancos Centrales en defensa del tipo de cambio en los mercados de divisas.

De hecho las crisis tienen su origen en los mercados financieros internacionales (incluyendo como tal al de divisas), y pueden tener un matiz cambiario, como las comentadas anteriormente, de deuda exterior o bancario como la situación que deriva de la crisis subprime en 2007. Estos tres tipos de crisis se pueden producir de forma aislada o conjunta y los costes económicos que suponen (medidos en términos de caída del PIB y pérdidas de empleo) son enormes.

Las variables explicativas de estas crisis combinan los aspectos de sobrerreacción de mercados y coherencia de las políticas de los países con las expectativas derivadas del gran poder de los operadores privados. En concreto como factores de vulnerabilidad se conjugan aspectos económicos y socio-políticos, entre otros, los tipos de cambio no-realistas, la fragilidad del sistema financiero nacional, políticas de privatizaciones o liberalizaciones poco prudentes, comportamientos excesivamente laxos de concesión de crédito, burbuja inmobiliaria, el desempleo, que de ser elevado disminuye el margen de maniobra de los gobiernos para adoptar políticas «duras» para defender la moneda; aspectos de corruptelas y/o inadecuada supervisión de los sistemas financieros domésticos, tan relevantes como los problemas de falta de regulación y supervisión del sistema financiero internacional.

${ }^{5}$ La evolución del dólar con el Euro desde su nacimiento en 1999 constata el tema. 
Ante este desorden financiero se plantea como objetivo la necesidad de combinar un rigor y credibilidad en las políticas económicas de los gobiernos, tanto en los aspectos macroeconómicos como los micro y estructurales (solidez de la relaciones industria-finanzas, supervisión adecuada de los sistemas financieros etc.), una supervisión y regulación internacional cuya «arquitectura» se está discutiendo. En este sentido se han señalado propuestas restrictivas o «códigos de conducta» de las instituciones financieras, supervisadas nacional e internacionalmente. Además, se discute la necesidad de crear o reforzar el FMI como «prestamista de última instancia» a nivel internacional, con un papel similar al de los bancos centrales a nivel estatal. Asimismo, la propuesta de articular un sistema pautado de «quiebras financieras internacionales», similar al que existe en los ámbitos nacionales, incluso con intervención judicial, está sobre la mesa.

\section{INESTABILIDAD EN EL MERCADO DE COMMODITIES}

El precio de los commodities ha evidenciado una notable volatilidad en los últimos años. Con la eclosión de la crisis en otoño de 2008 y su acentuación desde 2009 de nuevo hemos asistido a una impresionante evolución de los precios nominales entre 2007 y 2009 en un importante número de de commodities agrícolas, minerales y energéticas.

Históricamente han mantenido un patrón de precio reducido en términos reales, incluso ha seguido una senda decreciente en las décadas de 1980 y 1990 . No obstante la oscilación de precios en 2008 no tiene comparativa histórica, en parte fruto de la globalización e innovación financiera que ha aumentado la profundidad con la que operan estos mercados, cambiando la morfología de las series de precios ${ }^{6}$.

Como se muestra en la figura 3 en términos reales los precios de los commodities han descendido respecto a los máximos alcanzados a fines de la década del setenta. Lo hicieron de manera bastante marcada hasta el año 2001 donde alcanzaron su mínimo. El ascenso desde esa fecha hasta 2008 fue del 135\% aproximadamente. Entre los motivos cabe destacar la demanda de las economías asiáticas en estos mercados, especialmente el ascenso de China en la economía internacional, el exceso de liquidez mundial, la laxitud de las políticas monetarias y cuestiones de reducción de la oferta con la aparición de los biocombustibles. Si bien es cierto que el mercado sobrerreaccionó

${ }^{6}$ En los años 2004 las commodities se consolidaron dentro de los portafolios de inversionistas mundiales por medio de bolsas internacionales especializadas como la de Chicago o la Bolsa de Metales de Londres. 
por la llegada de liquidez especulativa provinente de otros mercados como el bursátil e inmobiliario. También se puede correlacionar con la depreciación continuada del dólar respecto el euro en los últimos años tal y como se observa en la figura 4

Figura 3. Índice de precios de los commodities en términos reales (escala logarítmica)

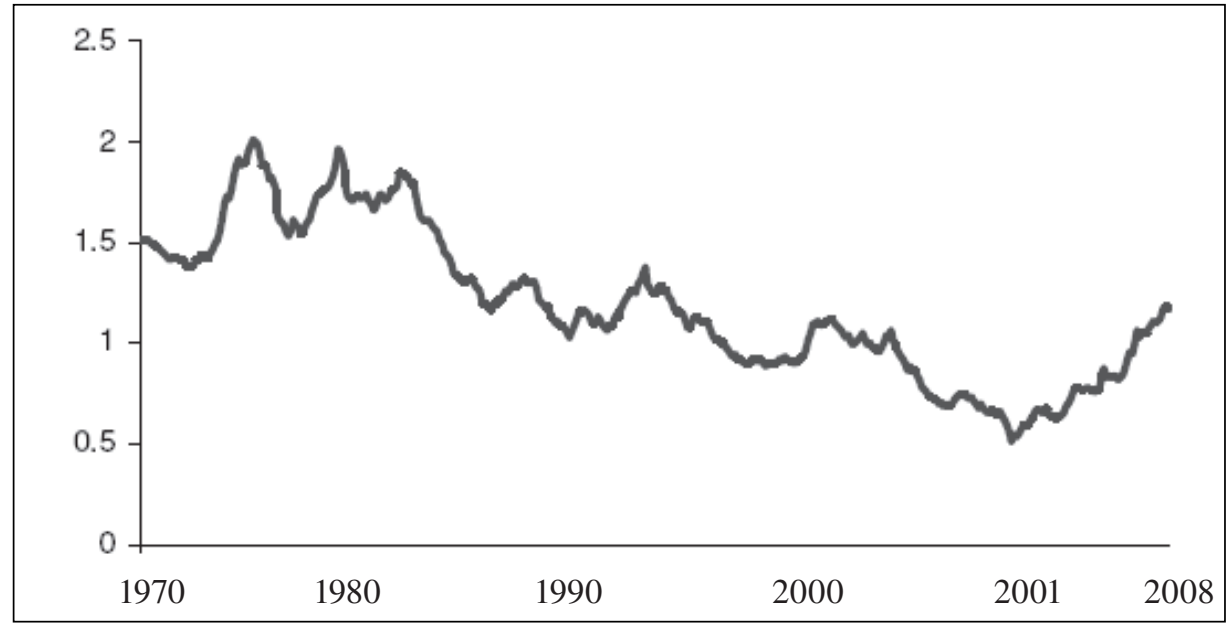

Figura 4. Evolución del Dólar y volatilidad de precios de commodities 2003-2008 (Serie de precios de commodities de exportación (f.o.b) en dólares USA $-2000=100$ )

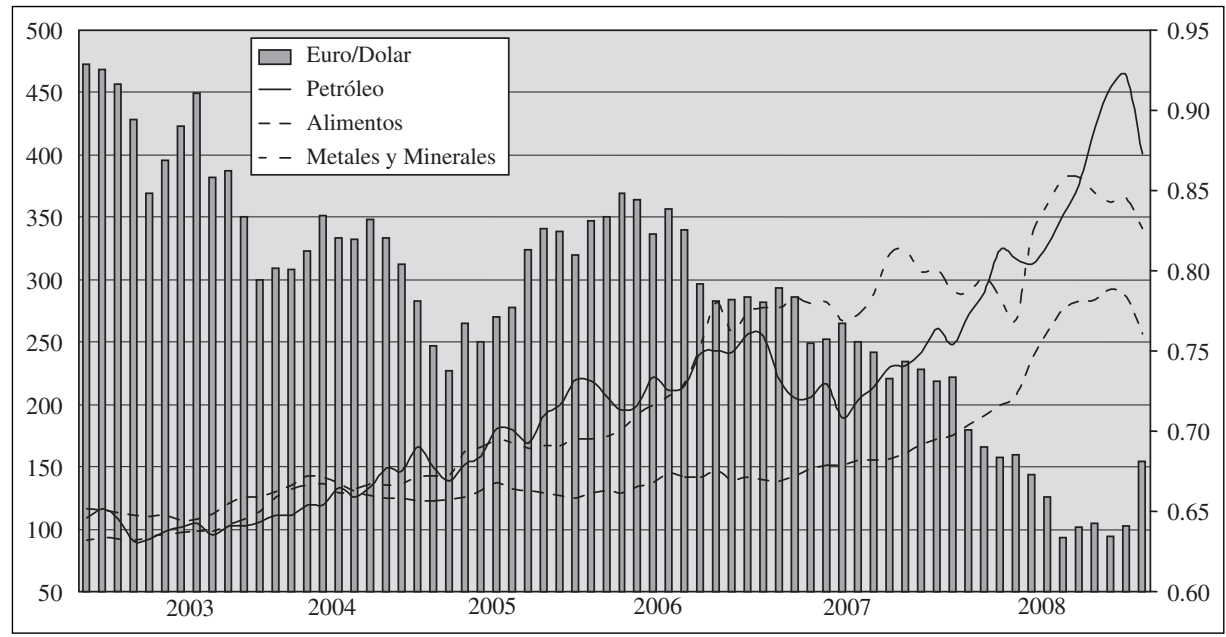

Fuente: The World Bank's Commodity y elaboración propia. 
Con expectativas a la baja en el mercado financiero y de la construcción la vía de escape en 2008 se centró en el mercado de commodities. Así, en los últimos años ha florecido el comercio de contratos estructurados como contratos de futuros, los «futures look-alikes» que se negocian en mercados electrónicos no regulados de tipo «Over the counter» que nadie controla porque son negociados directamente entre dos partes, sin salir al mercado y se les exime del deber de informar. Ciertamente, existen fondos cotizados que invierten en «commodities de papel». Esto significa que por cada commoditie se pueden llegar a negociar entre diez y veinte de papel, ello sucede con el barril físico de crudo y ello es fácil de observar si pensamos que los contratos de futuros sobre petróleo han pasado en los últimos dos años de dos billones de dólares a nueve billones y han formado parte de una multitud de fondos de inversión «indexados» a la evolución de los precios del barril de petróleo y otras materias primas (en su mayoría relacionados con Goldman Sachs, Morgan Stanley, Citigroup y JPMorgan Chase) y que han conformado una opción de los inversores para protegerse de la inflación y con una rentabilidad dependiente de unas expectativas autorrealizantes.

El debate en este contexto está centrado en las considerables consecuencias desestabilizadoras del incremento del precio de alimentos y materia primas sobre los consumidores, sobre la inflación y sobre su impacto global sobre los patrones de comercio o sobre el sistema monetario internacional, en tanto éstos se habían convertido en un activo de inversión sustitutivo al de los mercados financieros. Y todo ello difícil de manejar desde un punto de vista de política nacional, evidenciando de nuevo la situación del dilema de política social antes analizado.

De hecho las externalidades negativas de los movimientos de precios de commodities son potencialmente variadas dependiendo del tipo de materia prima y de economía que se esté considerando. En este sentido, en las economías desarrolladas, los commodities no representan una parte significativa de la canasta de consumo de los hogares a diferencia de las economías menos desarrolladas (en concreto representa «sólo» un $10 \%$ en los países de la OCDE (FMI, 2007)) . No obstante, el peso de los alimentos en la canasta de consumo promedia aproximadamente un $65 \%$ en África subsahariana y un $30 \%$ en Asia, pudiendo acarrear una crisis alimentaria y graves desajustes macroeconómicos.

Lo mismo sucede con el petróleo. En los años 1970-80's las economías desarrolladas eran muy sensibles a las subidas — shock de oferta - no obstante su importancia relativa ha descendido en los últimos años tanto sobre el PIB (por la menor intensidad de uso), como sobre la inflación (por el menor poder de repercusión de los costes al precio en un mercado competitivo mundial). Este fenómeno se ha observando en todas las economías industrializadas en los últimos años. No obstante, sí que afectaría relativamente más a los países de desarrollo intermedio como los latinoamericanos donde la 
estructura productiva tiene un importante sustento en el sector primario, de modo que una volatilidad en el precio de las commodities impacta directamente sobre el conjunto de variables macroeconómicas. En el caso de las economías petroleras la volatilidad en la cotización altera radicalmente el PIB.

De hecho los países pequeños que basan su PIB en un monocultivo son muy sensibles a los precios de exportación, determinantes de su evolución macroeconómica a la baja en épocas de reducción de precio y también en determinados casos de subida del precio si ello incide en la apreciación de la moneda local - fenómeno conocido con el nombre de enfermedad holandesa- Por otro lado, trabajos como el de Sala-i-Martin y Subramanian (2003) señalan el vínculo entre producción de petróleo o minerales y crecimiento económico, sobresaliendo la idea de que la abundancia de tales recursos naturales puede actuar como una «maldición» si la búsqueda de su control propicia corrupción y corroe las instituciones.

También los ingresos fiscales son afectados por los acontecimientos en estos mercados, como lo demuestra la creciente importancia financiera global de los Fondos Soberanos de Riqueza (FSR), cuyo origen se asocia muchas veces a la propiedad pública de commodities estratégicos.

Finalmente unos precios muy volátiles plantean problemas a la hora de implementar políticas de estabilización y de reducción a la dependencia de los commodities. La idea es que en la fase ascendente del ciclo de precios la economía experimenta un alza en las exportaciones, los ingresos fiscales y el producto, por lo que no existen incentivos políticos para implementar medidas innovadoras tendentes a la diversificación productiva, aunque tal vez se disponga de recursos con los cuales intentar abordar las mismas. En la fase de bajada de precios, por otra parte, el deseo del poder político por acotar la influencia de las commodities será mayor, pero es más probable que se carezcan de los medios y del contexto favorable para llevar a cabo las acciones pertinentes.

Para el caso de otras commodities energéticas como el gas o la electricidad, se producen también situaciones como los analizados en forma de dilemas triples y que pueden acarrear crisis energéticas. Así por ejemplo, países como España o Portugal entre otros, están condenados a ser largo tiempo una isla energética respecto a Europa y no hay que olvidar que no existe ninguna política energética común europea y cada Estado es soberano en este campo.

En este ámbito si aceptamos como deseable la total autonomía en el diseño de la seguridad de abastecimiento hasta la aceptación de que el mercado europeo será una realidad, el elemento a controlar es, obviamente, el de la pérdida de jurisdicción. Pero debe olvidarse uno completamente de la estabilidad regulatoria. Sin duda las reticencias a la cesión de jurisdicción a favor de un mercado supranacional no son ajenas a 
ellas. La senda de precios en España, los derechos de los Contratos de Adquisición de Energía, CAE en Portugal y la necesaria armonización de las regulaciones entre ambos países son temas que sin duda deberán ser abordados. Todos ellos afectan la estabilidad regulatoria.

Otra arista del trilema es el referente al tránsito hacia el escenario europeo pero manteniendo una cierta estabilidad regulatoria. Es el caso del control sobre fusiones y adquisiciones a nivel comunitario. Para este análisis debe abandonarse toda reflexión sobre autonomía energética de un estado miembro concreto. En España, todos los intentos en este sentido han sido fallidos debido sobre todo a los miedos, por parte del Gobierno, en una excesiva concentración y por parte de la industria a una percepción de excesiva discrecionalidad de la Administración (casos Endesa-Iberdrola y el más reciente Gas Natural - Iberdrola). Otros ejemplos en el ámbito europeo han sido las autorizaciones de concentración por parte de la $\mathrm{CE}$, con condiciones. En cualquier caso, empresas españolas controladas por grupos energéticos extranjeros supondrían pérdida de control sobre la autonomía energética.

\section{Conclusiones}

El trabajo presentado ha analizado las diferentes opciones de política económica posibles en un mundo global, incorporando la dimensión económica, política y social. Las opciones de política económica se han singularizado en forma de «dilemas triples» de la Globalización. Con ello, además, se ha querido poner énfasis en el problema de elección entre lo deseable y lo factible, en un contexto en el cual se manifiesta la imposibilidad de mantener simultáneamente objetivos económicos y sociales claves. El punto de arranque del problema tiene que ver con el impacto de la globalización en mercados como el comercial, financiero o el de commodities en un marco, como el actual, donde el ámbito territorial y decisorio de lo político (estados-nación) no coincide con el ámbito territorial de lo económico (el mercado es el mundo).

En este escenario, los movimientos internacionales de capital, en especial a corto plazo, ejercen una influencia decisiva sobre los mercados financieros, sobre las divisas, sobre el precio de las commodities y sobre la eficacia de políticas nacionales de estabilización macroeconómica. Adicionalmente, y no por ello con menor alcance, la globalización también origina conflictos en el ámbito político-social. La coherencia de la correspondiente argumentación, de todas formas, descansa en aceptar como algo deseable participar en el proceso globalizador en el sentido de que, en resumidas cuentas, sus ventajas en el ámbito económico superan a los respectivos inconvenientes. 
Con este punto de partida resulta, entonces, que no es viable conseguir simultáneamente mantener la soberanía nacional de los estados a nivel convencional, disponer de las estructuras propias del estado del bienestar y participar plenamente en el proceso globalizador.

En efecto, el ejercicio de las prerrogativas de soberanía nacional concretadas en disposiciones administrativas, reglamentaciones y actuaciones supervisoras (básicamente en el marco laboral, medioambiental y financiero) e implantar a la vez los atributos propios del estado del bienestar, excluye a los países del proceso globalizador por razones competitivas. Si, alternativamente, se opta por participar en lo global y mantener las prerrogativas propias de soberanía nacional, entonces se resquebraja, por razones de eficiencia, la estructura propia del estado del bienestar. Y, en fin, participando igual en el proceso globalizador y manteniendo las bases de una política social en términos de equidad, resulta que, en este caso, debe renunciarse a niveles de soberanía por relajación de normas y reglamentaciones.

En la medida en que la globalización sea una realidad, son los otros dos aspectos los que a la postre resultan minorizados. Porque, la cada vez mayor autonomía que la globalización otorga al capital, lleva a aumentar el poder de las estructuras productivas en contra de políticas sociales y medidas de salvaguarda de todo tipo. $\mathrm{Si}$, en este contexto, cada país pretende, entonces, actuar exclusivamente en función de sus propios intereses, se llega a una situación propia de «dilema del prisionero», obteniéndose el peor de los resultados a nivel global.

En definitiva, se han puesto de manifiesto importantes disfuncionalidades del proceso global. Su constatación es un referente que, por el momento, no ha propiciado la necesaria reordenación de las finanzas internacionales. Y si eso es así en el ámbito económico, en el relativo a lo político-social los planteamientos oportunos aún se debaten en terreno más lejano, puesto que implementar normas de «federalismo global», ni siquiera en aspectos tímidamente parciales, no es objeto de preocupación inmediata. De esta forma, a medida que el fenómeno de la globalización se consolida, se agrandan sus inconvenientes al no encarrilar sus ventajas evidentes.

Con la acentuación de la crisis económica en 2009 ha resurgido el debate sobre las opciones de política económica, confrontando el discurso liberal, la opción keynesiana y la proteccionista. Y parece que sean los únicos debates posibles, esto es, el debate histórico (no resuelto aún hoy) entre: ¿Son mejores las políticas de eficiencia o las de equidad?

Parece razonable que hoy la economía global necesita de una política global (al igual que cuando la economía era nacional la política requerida para corregir los fallos del mercado debía ser nacional). De hecho, a una escala menor, para contrarrestar la 
globalización los Estados-nacionales ya se han visto obligados a promover una integración supranacional de los espacios económicos (Unión Europea). Y ello, ha comportado renunciar a soberanía (tipos de cambio, tipos de interés, a determinados sistemas fiscales, etc.).

Asimismo, en gran parte la dinámica de la globalización está originando una creciente polarización, una creciente desigualdad dentro de y entre los países, y una inestabilidad en los mercados, desde el financiero al de commodities y ello requiere algunos mecanismos de estabilización de los mercados y de coordinación y compensación política-social «razonables». Es decir, requiere la articulación de políticas a nivel intergubernamental. Se trataría, además, de pactar a nivel internacional en materias como por ejemplo la financiera, fiscal, laboral, energética, alimentaria y medioambiental.

En resumen, para conseguir simultáneamente los objetivos de eficiencia y equidad la globalización política deberá coger el ritmo de la globalización económica y financiera.

\section{REFERENCIAS BIBLIOGRÁFICAS}

1. Rodrik, D. (2000), «How Far Will International Economic Integration Go?», Journal of Economic Perspectives, Winter 2000. págs. 177-186.

2. Rodrik, D. y Persele, Y. (2001), «When Does International Capital Mobility Require Tax Coordination?», Journal of International Economics, vol. 54, no. 1, págs. 57-73.

3. Summers, L. (1999), «Reflections on Managing Global Integration», Journal of Economic Perspectives, primavera, 1999, págs. 3-18.

4. FMI (2007), «Global Prospects and Policies», World Economic Outlook (Capítulo 1), Octubre de 2007.

5. Sala-i-Martin, X. y Subramanian, A. (2003), «Addressing the Natural Resource Curse: An Illustration from Nigeria», IMF Working Paper 03/139, julio. 